\title{
The Science and Technology Incentive Mechanism in Russia: A Chronicle of 1990-2020
}

\author{
Elena Korostyshevskaya ${ }^{1, *}$, Olga Stoianova ${ }^{2}$, and Gennady Alpatov ${ }^{1}$ \\ ${ }^{1}$ St. Petersburg State University, Economic Faculty, Department of Economic Theory, 7/9 \\ Universitetskaya nab., St. Petersburg, 199034, Russia \\ ${ }^{2}$ St. Petersburg State University, Economic Faculty, Department of Information Systems in \\ Economics, 7/9 Universitetskaya nab., St. Petersburg, 199034, Russia
}

\begin{abstract}
Research background: The analysis shows the focus of studies on public incentive for science and technology (S\&T) on individual tools (financial support, personnel development, infrastructure, scientific collaborations), or the study of the current issues. The development of a systemic view on the evolution of the public mechanism of S\&T incentive is required.

Purpose of the article: to form a systemic view on the processes and instruments of S\&T stimulation in Russia over the past 30 years, allowing to create a methodological basis for centers of excellence development.

Methods: A comprehensive historical and logical analysis of Russian and foreign studies is conducted. Using a systemic approach, a classification of S\&T incentive instruments is developed, which is greatly influenced by the ideas of S. Zaichenko on centers of excellence. Quantitative analysis of S\&T statistics in the context of the implementation of various public incentive mechanism instruments allows to draw conclusions about the level of effectiveness of the latter. On the basis of the synthesis of all the results obtained, proposals for the structure of the mechanism for stimulating centers of excellence in Russia are generated.

Findings \& Value added: - S\&T stimulation tools in Russia over the past 30 years are identified and classified; - a periodization of these instruments is developed; - a chronological analysis of their evolution in the context of the selected groups and their influence on the innovative development of Russia is conducted; - proposals on the structure of the mechanism for stimulation of the centers of excellence in Russia are formulated.
\end{abstract}

Keywords: science; technologies; innovations; public policy

JEL Classification: $B 52 ; D 02 ; E 32 ; O 32$

\footnotetext{
*Corresponding author : e.korostyshevskaya@spbu.ru
} 


\section{Introduction}

\subsection{Research background}

The issues of state stimulation of science and technology, despite their elaboration, are still of great research interest. This is due to the multifaceted nature of the problem, including such areas as financial support of research (Albert, 2018), the development of human resources (Stoianova and Bakotin, 2018), innovative development of companies (Stoianova et al, 2020), infrastructure support of scientific and technological development (Kobylińska, 2020), support of various forms of research collaborations (Kutsenko, 2015; Korostyshevskaya and Chudakov, 2019; Korostyshevskaya, 2018), commercialization of innovations (Cerulli, 2016; Korostyshevskaya et al, 2018), research and development management (Stoianova and Moskaleva, 2021). The analysis of publications has shown that the major issue is the study of certain incentive tools in the above stated areas, or the study of the issue at the present moment. In our opinion, there is a need to develop a systemic view on the evolution of the structure of the state mechanism for the stimulation of science and technology development.

\subsection{Purpose of the article}

To develop a systemic understanding of the processes and tools for the stimulation of science and technology in the new Russia over the past 30 years which will create a methodological basis for the development of world-class centers of excellence in the country.

\subsection{Purpose of the article}

To develop a systemic understanding of the processes and tools for the stimulation of science and technology in the new Russia over the past 30 years which will create a methodological basis for the development of world-class centers of excellence in the country.

\section{Methods}

The study provides a comprehensive historical and logical analysis of the works of Russian and foreign scientists devoted to the development of science and technology in Russia for the period from the 1990s to the present moment. Using a systemic approach, a classification of tools for the stimulation of science and technology was created, which was greatly influenced by the ideas contained in the work of S.A. Zaichenko on the centers of excellence (Zaichenko, 2008). A quantitative analysis of state statistics data in the field of science and technology and comparison with various components of the state incentive mechanism made it possible to substantiate conclusions about the effectiveness of the latter. Based on the synthesis of all the results obtained, proposals were developed on the structure of the mechanism of state incentives for the creation of centers of excellence in Russia.

\section{Results}

The analysis made it possible to identify the following key tools for the stimulation of science and technology in Russia over the past 30 years:

- programming (an active component of public policy),

- policy for human resources development,

- creation of infrastructure for research and development, 
- investment.

The study is based on the author's periodization of the tools to stimulate science and technology used in Russia in 1990 - 2020:

- 1991 - 2000 the collapse of the USSR. Lost years and projects,

- 2001 - 2009 "Fat years",

- 2010 - present - Inconsistent stabilization,

The period preceding the collapse of the USSR (1985-1991) included gradual degradation of the planned administrative and team system, which ended with shock therapy (1992-1998), all this presupposes a quick and radical transition to the market. The result of this transformation of the country's socio-economic system was the default of 1998.

2001 - 2009 - "fat years" in the economic development of Russia is characterized by high incomes from the sale of raw materials at the world market. The National Welfare Fund is created, and regional programs are implemented.

The period of inconsistent stabilization that began in 2010 is characterized by constantly recurring economic crises, the series of which ends with a pandemic.

Below the results of a chronological analysis of the evolution of tools for science and technology stimulation in the context of the identified classification groups and an assessment of their impact on the innovative development of Russia are presented.

\subsection{Programming (active components of public policy)}

\section{1 - 2000 Collapse of the USSR. Lost years and projects}

During the period under review, most programs aimed at the development of science and technology and the strategic centers of excellence were stopped. For example, the Buran program, one of the brightest examples of the national cosmonautics, was curtailed in the early 1990s. The Russian Federation inherited from the USSR the experience of creating and launching into orbit the Salyut orbital stations (1971-1991), as well as the Mir station (19862001), in the early 90s it was planned to create the Mir-2 station, but due to economic difficulties, the project was suspended.

At the same time, some programs were implemented. In 1992 the Russian Federation and the United States developed together a joint Mir-Shuttle program. The largest space project of the 21 st century is the International Space Station (ISS). It has been in operation since the end of 1998. In the early 90s the development of a new rocket "Angara" started.

During this period, programs aimed at the development of systemic centers of excellence were implemented. In 1992-1994 programs for the development of state scientific centers (SSC) were designed. The SSC development program was launched on June 22, 1993. The overwhelming majority of the RF SSC are organizations of the military and industrial complex, trying to develop and implement conversion programs in the context of reforms. In the USSR, they were mainly large "mailboxes" with tens of thousands of workers, a wellorganized system of pilot production facilities, well-equipped with modern, in many cases imported equipment. Up to $90 \%$ of orders and funding came from military ministries and organizations.

During this period, a program was adopted to support a number of sectoral institutes, recognized as "state research centers of the Russian Federation." At the end of 1995, there were 65 of them (Avdulov and Kulkin, 1996).

The Federal Target Program "Research and Development in Priority Areas of Development of the Scientific and Technological Complex of Russia", the purpose of which is to form an efficiently functioning R\&D sector in the field of applied research, has started since 1996. 
As for the programs aiming to support the development of experimental centers of excellence, they were aimed at the development of universities then and later. These programs are discussed in more detail in the next section.

2001 - 2009 "Fat years"

Among the programs for the development of strategic centers of excellence related to the period under review the following could be mentioned: "State Armaments Program (2001 2010)"; Federal Target Program "Reform and development of the Defense and Industry Complex (2002-2006)"; Federal Target Program "Development of the Defense and Industry Complex of the Russian Federation" for 2007-2010 and for the period up to 2015. The Federal Space Program of Russia for 2001-2005 and FTP "Global Navigation System" (since 2001) was launched.

In addition to the SSC, system centers of excellence were developed on the basis of stateowned companies (state corporations), financial and industrial groups. An example of a program aimed at the development of system centers of excellence is the Federal Target Program "Development of Civil Aviation Equipment in Russia for 2002-2010 and for the period up to 2015". The goal of the program is to achieve the competitiveness of the civilian sector of the aviation industry, and to create a world center for aircraft construction. Similar programs were implemented in the field of the development of the electronic, radio-electronic industry, and shipbuilding.

\section{0 - present Inconsistent stabilization}

Programs for the development of strategic centers of excellence are developed and implemented mainly in the field of space research, defence and the development of nuclear projects. Among them - "State Armament program for 2011-2020", "Program of Activities of the NRC "Kurchatov Institute" for 2018-2022"; Lunar program "Roscosmos" - 2021; Program "Luna-25"; FTP "Maintenance, development and Use of the GLONASS system for 2012-2020"; "Federal space Program for 2016-2025" with funding of almost 3 trillion RUR for 10 years, but in fact only 1.6 trillion RUR was allocated (Zheleznyakov, 2017).

An example of a strategic center of superiority of a new type is the Novosibirsk Scientific Center (NSC). In accordance with the instructions of Vladimir Putin of April 18, 2018, a program for the development of the NSC, as well as the "Integrated Development Plan of the SB RAS" and the Akademgorodok 2.0 project were adopted, the purpose of which is to create the most powerful world-class scientific center in the country.

In the period under review, the concentration of efforts is aimed at the support of the previously created systemic centers of excellence based on state corporations. For example, the Program of Innovative Development of JSC RusHydro is implemented in 2011-2015, 2016-2020 with a prospect until 2025 based on the program results of 2018. But according to experts, similar programs for innovative development of companies with state participation started in 2010-2011 are not really innovative programs, but strategies for the catch-up development of state corporations (Alexandrov, 2013).

\subsection{Policy for Human Resources Development}

\section{1 - 2000 Collapse of the USSR. Lost years and projects}

Universities became the main institute for human resources training for the field of science and education in the period under review. The presidential target program "State Support for the Integration of Higher Education and Fundamental Research for 1997-2000 and up to 2005" was launched. As a result of this program, 300 educational and research centers (ERC) were founded on the basis of universities. 
2001-2009 "Fat years"

As part of the development of experimental target programs, the program "Fundamental Research and Higher Education" is implemented. In 2006, programs aimed at strengthening the innovative potential of universities are launched, including the national project "Education", "Innovative Educational Program (IEP) of Universities" for 2006-2008. The universities are merged, federal universities are founded. In 2008, a Presidential Decree was issued on the establishment of National Research Universities, and the program "Education and Development of an Innovative Economy: Implementation of a Modern Education Model for 2009-2012" was started.

\section{0 - present Inconsistent stabilization}

This period is characterized by the greatest activities in support of the development of experimental target programs and human resources in science and technology. The state realized the importance of universities as target programs and increased attention to their development, in particular, in the form of the so-called "excellence initiatives" that took place in a number of countries in the last 20-30 years (China, Germany, France, Japan, etc.) ... In Russia, this form of support was purposefully implemented in the form of the "5-100" Program, which was further continued as the "PRIORITY-2030" strategic academic leadership program.

It should be noted that by the beginning of the 90 s, Russian science lost a significant part of its human resources. In two "cities of science" of the Moscow region - in the city of Chernogolovka (Noginsk Scientific Center, 1963) and in the city of Pushchino - the total population losses were $15.8 \%$ and $9.4 \%$, respectively, in the institutes of Moscow and St. Petersburg - 12, 2\%, and in the Novosibirsk Academgorodok - 12.5\% (Avdulov and Kulkin,1996). The current situation continued to worsen up to the present moment (Alpatov and Anokhina, 2021).

As the number of personnel involved in research and development was rapidly reduced, newcomers were needed, it was necessary to strengthen the higher education system for their training. Note that in the 1930s there were about 700 universities in the USSR (Shulgina, 1988) and by 2000 there were only 390 (according to Federal State Statistics Service of the Russian Federation, https://rosstat.gov.ru/). Over the next 10 years, there was no significant increase in the number of universities, then only by 2014 the number of universities reached the level of 1930s. The sharp increase in their number in 2015 up to 1,040 is due to the development of private universities and the expansion of their networks. In subsequent years as a result of the merger of universities and the closure of a number of ineffective commercial organizations in this area, their number stabilized at an average level of 950 establishments.

Note that the growth in the number of universities did not lead to an increase in the number of personnel engaged in research and development, i.e. did not contribute to the development of human resources in research. In general, over the past 10 years the number of researchers in the Russian Federation decreased by $28.6 \%$ (from 518.7 thousand people in 1995 to 370.4 thousand people in 2016, while in other developed countries this number grew up (Petrov and Kurakova, 2019). In our opinion, the key reason for this was the reduction in the number of jobs for specialists engaged in research and development.

\subsection{Development of research and development infrastructure}

\section{1 - 2000 The collapse of the USSR. Lost years and projects}

SSE, which focus on military R\&D, act as strategic centers of excellence. There are 17 of them in the defense industry, 6 - in the nuclear power industry. The sector of military scientific organizations in Russia has more than 650 research institutes and design bureaus. 
From 1991 to 1995 they got about $70 \%$ of the budgetary allocations for science in the country. In order to support the civil sector of science, they launched a program for the development of a number of sectoral institutes, which are recognized as "state scientific centers of the Russian Federation" and are considered as systemic centers of excellence. At the end of 1995, there were 65 of them (Avdulov and Kulkin,1996). In 1998 a new initiative was launched to create experimental centers of excellence. 20 Research and Educational Centers (REC) were established and focused on the integrated development of science, education and external relations with the participation of American experts, and they turned out to be more effective than the centers of excellence. For the first time universities on the basis of REC obtained equipment, in terms of its novelty and parameters exceeding the one available at the institutes of the Russian Academy of Sciences (Dezhina, 2020).

\section{1 - 2009 "Fat years"}

In 2008, the President of the Russian Federation signed Decree No. 603 "On a pilot project to create a national research center "Kurchatov Institute", which served the basis for the development of strategic centers of excellence not only in military field, but also in other fields of research. System centers of excellence developed mainly on the basis of state corporations in the fuel and energy complex under conditions of high oil prices. However, state corporations retain weak (mainly administrative) motivation and non-market technological competencies, as well as financial and industrial groups. Medium innovative companies start their development. SSC continued to develop.

Experimental centers of excellence are represented by federal universities - 10 (2006) and national research universities - 29 (2008). The first joint laboratories with foreign researchers began to appear in the 2000s (before the Mega-Grants Program). Among them are "mirror laboratories", then the project of creation of 1000 laboratories (Program "1000 laboratories"), which was never implemented (Dezhina and Ponomarev, 2013), but its modification appeared as part of the "5-100" project.

\section{0 - up to now Inconsistent stabilization}

The main strategic centers of excellence in this period, which until that time were part of the system centers of excellence, are the National Research Center "Kurchatov Institute" with a new status obtained in 2010 (the first link in the system of atomic science); Novosibirsk Scientific Center (NSC); Federal Research Center for Research and Development of Immunobiological Drugs named after Chumakov, RAS; State Research Center of Virology and Biotechnology "Vector", created to counter global infectious threats; Scientific Center of the Russian Academy of Sciences in Chernogolovka, which includes 7 academic institutes. Among the systemic centers of excellence, in addition to the state corporations of the fuel and energy complex, Rostec State Corporation begins to stand out, which develops, manufactures and markets globally competitive military and civilian products, developed on the basis of unique technological competencies. The United Shipbuilding Corporation demonstrates a certain potential. However, most of the series of manufactured ships are projects of foreign design bureaus (Tresoruk and Frolov, 2020). Technological innovation platforms emerge: Composite materials, LEDs and energy saving, Biotechnology, Avionics and airborne equipment. Basic departments of leading state universities function in almost all centers of excellence. Since the beginning of 2010 federal research and production centers have been established. This status is assigned to certain enterprises and organizations of the defense, rocket-space and nuclear industries that work on the state defense order.

Within the framework of experimental CPUs, in 2010 the laboratories were launched with the participation of leading foreign scientists, incl. representatives of the Russian-speaking scientific diaspora. During the period "5-100", 272 laboratories were opened at universities. For example, at the St. Petersburg National Research University of Information 
Technologies, Mechanics and Optics, 5 centers of excellence have been created on the basis of international laboratories (Photonics and Natural Sciences, Smart Materials, Sciences and Life and Health, Intelligent Technologies and Robotics, Information Technologies in Economics, Social Field, Art).

The government plans to create World-Class Research Centers (WCRC) as an instrument of "scientific breakthrough". In the Russian Federation, at the expense of mega-grants (28.7 billion rubles of the state budget and 7.6 billion rubles of extra-budgetary funding), 160 world-class scientific laboratories have already been created (Petrov and Kurakova, 2019). As part of the Priority 2030 Program, it is planned to create up to 120 universities (20202025) in 2021 - 2024 with funding amounting about 52 billion rubles. The trends in the research and development infrastructure are illustrated by the data in Figure 1.

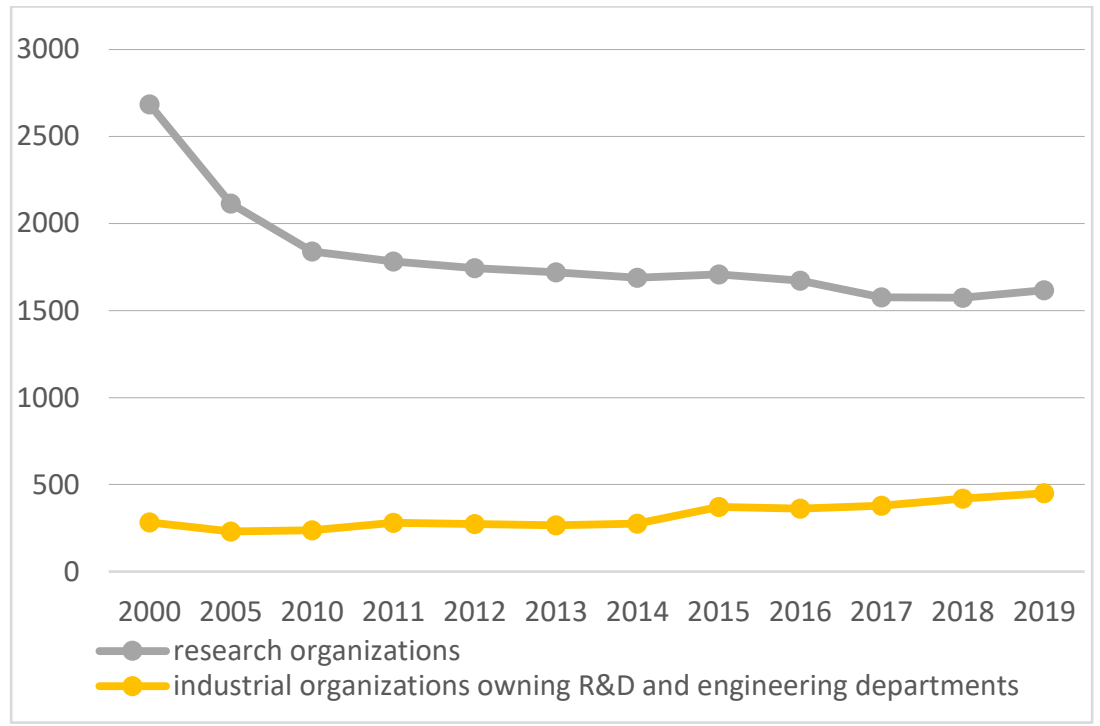

Figure 1. The number of organizations that carried out research and development, pcs.

Source: Federal State Statistics Service of the Russian Federation, https://rosstat.gov.ru/

Figure 1 shows that since 2000 the number of organizations engaged in research and development has seriously decreased, primarily due to the number of research institutes. And if in 2000 the number of research institutes was 2686, then by 2019 there were 1618 of them, while in the former USSR in the 1960s there were 3548 research institutes (Shulgina, 1988), i.e. a decline of more than 2 times is observed in that case. At the same time, such a sharp decline is not offset by the growth of internal research and development departments of the companies. The reason, contrary to popular belief, is not only the lack of funding, which is confirmed by the data in Figure 2. 


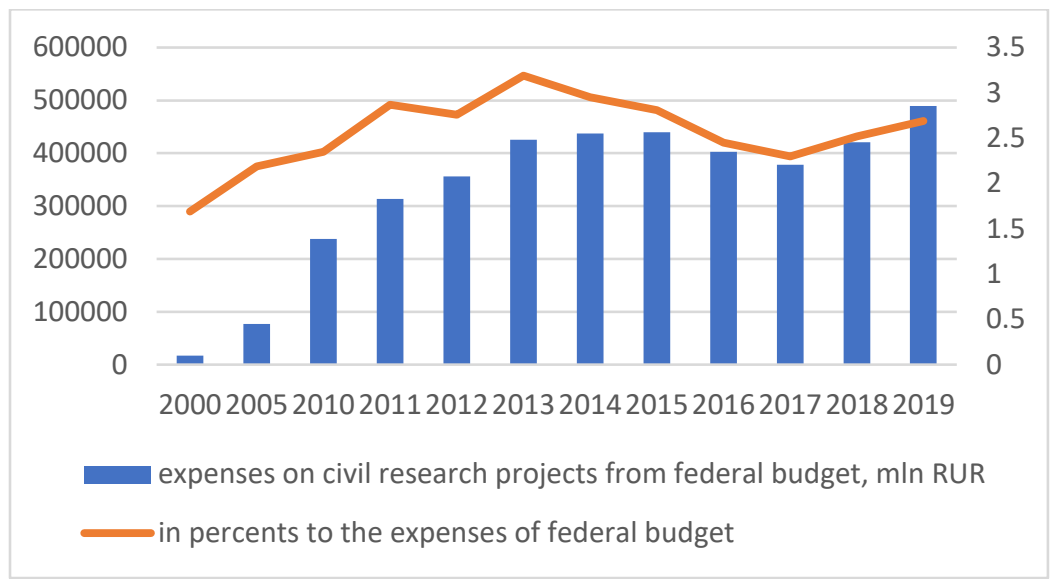

Figure 2. Research funding from the federal budget.

Source: Federal State Statistics Service of the Russian Federation, https://rosstat.gov.ru/

\subsection{Investments}

The issues of science and technology funding are considered further in an aggregated form for the entire period under consideration, since this allows to visualize the main trends. The period before 2000 was the most difficult for Russian science, practically no funding was allocated for civil projects, and the data on funding for defense programs are not available.

Although in the 2000s problems with funding for research were really observed, then from 2010 to 2015 there was a significant increase in allocations from the federal budget for science. After 2015 there is a slight decline with a trend towards further recovery. At the same time, attention is drawn to the fact that the share of expenditures on science in the total expenditures of the federal budget starting from 2013 was falling with a slight recovery since 2018. For this indicator, 2019 is comparable to 2010, i.e. in fact, there was a return to the level of funding that was observed ten years ago.

As for the internal costs of companies on $R \& D$, they are steadily growing in current prices. But the share of such costs (Figure 3) still remains low (about 1\%) compared to developed countries, where the average share is $2.5-3.5 \%$ of GDP.

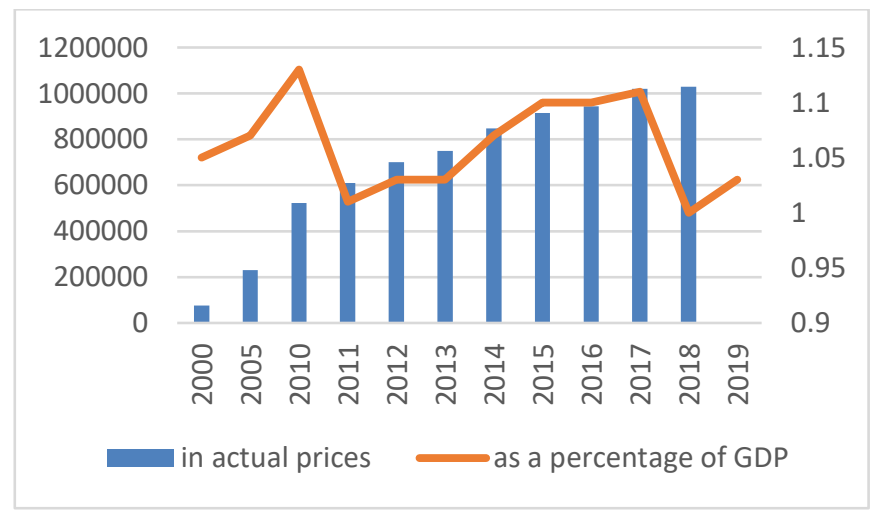

Figure 3. Internal costs on R\&D, mln RUR.

Source: Federal State Statistics Service of the Russian Federation, https://rosstat.gov.ru/ 
It should be noted that sources of funding for science include not only federal budget and internal funds of companies, but also resources of development institutions. These include the Russian Fund for Technological Development, the Fund for Assistance to the Development of Small Forms of Enterprises in the Scientific and Technical Sphere, the Russian Bank for the Support of Small and Medium-Sized Businesses, the Bank for Development and Foreign Economic Affairs (Vnesheconombank), Russian Venture Company (RVC), Rusnano Fund for Infrastructure and Educational Programs; Development Fund of the Center for the Development and Commercialization of New Technologies "Skolkovo" ("Skolkovo"); Seed Investment Fund of RVC; RVC Infrastructure Fund; RVC International Funds - Russian Venture Capital.

\section{Discussions}

The analysis shows all the stimulation tools for the development of science and technology were used in the historical perspective under consideration.

Regarding the active component of economic policy (programming), the following main aspects can be revealed. First, in the latest of the identified periods (from 2010 to the present moment), there is a new trend in strategic centers of excellence which are launched not only on the basis of defense projects, but also projects for the development of fundamental science in civil research fields. Second, the programs for support and development of systemic centers of excellence are the weakest and least diverse in comparison with programs associated with strategic and experimental centers of excellence.

Regarding the development of human resources, it should be noted that the state is actively engaged in the development of conditions for the training of qualified personnel in science and technology at all stages. However, the effectiveness of the measures taken remains low. There are many programs, while the same program is extended 2-3-4 times and their goals have not been achieved for 30 years.

While the development of national projects, president Vladimir Putin proposed the National Project "Science and Universities", which includes 4 federal projects, one of which is "Personnel". This project sets two possible trends of development - the creation of Competence Centers in certain narrow areas demanded by the market, or the search for large contracts in the interests of industry. There are few examples so far. In order to support the second trend, the necessary infrastructure is proposed to be provided through federal projects "Infrastructure" (aimed at creating infrastructure both in universities and scientific organizations), "Research Leadership" (aimed at achieving significant results in the priority strategic areas of development of the Russian Federation) and "Integration" (uniting universities, research organizations and leading enterprises into consortia aimed at breakthrough research). The implementation of the last of the above listed projects, in our opinion, will facilitate the transformation of experimental centers of excellence into systemic centers of excellence.

Another important observation of this study also concerns systemic centers of excellence. In the last period (from 2010 to the present), for the first time, the development of systemic centers of excellence occurs not only at the will of the state, but as a result of private initiative. Applicants for inclusion in the systemic centers of excellence are actively developing medium-sized companies from the ratings "National Champions" and "Techuspech". There are all in all 400 growing companies that have not yet entered large-scale markets, but are already demonstrating growth potential (Medovnikov et al, 2016). Striking examples include the companies "Geropharm" and the Research and Development Center CJSC "Biocad" (one of the top 30 in the world) (Simachev and Kuzyk, 2020).

In order to develop systemic centers of excellence into strategic ones, at the end of 2014, by the Decree of the President of the Russian Federation, the National Technology Initiative (hereinafter - NTI) program was launched, the purpose of which is to determine the most 
promising markets of the future with a capitalization of $\$ 100$ billion for the next 15-20 years. The State Program of Scientific and Technological Development (approved by Decree of the Government of the Russian Federation No. 377 of March 29, 2019) and the National Projects: Science, Education, Digital Economy are aimed to achieve that goal (Ivanov, 2019). Integration of science and industry is the basis for the creation of strategic centers of excellence. This is the focus of the new version of the Federal Target Program "Research and Development in Priority Areas of Development of the Scientific and Technological Complex of Russia" (for 2014-2020) (Zelentsova, 2017).

It is important to note the impact of the Covid-19 pandemic on the evolutionary processes in the system of centers of excellence. This is manifested in the acceleration of the transition of systemic centers of excellence into strategic ones. For example, the State Research Center for Virology and Biotechnology Vector, as a basic structure for one of the three world-class genomic centers, can develop as a National Research Center similar to the model of Kurchatov Institute.

All the above stated makes it possible to make proposals on the structure of the mechanism of state incentives for the creation of centers of excellence in Russia. In addition to the tools discussed in the context of globalization and regionalization, an important role will be played by technological platforms that currently exist but are not built into the current mechanism. Also, regional innovative industrial clusters, whose cores are the largest system centers of excellence, will influence a lot as integral elements of the mechanism.

\section{Conclusion}

During the survey, the following main results were obtained:

- The key tools for stimulating science and technology used in Russia over the past 30 years are identified, their classification characteristics are presented.

- A periodization of the tools for science and technology stimulation used in Russia from 1990 to 2020 is developed.

- Based on the proposed periodization, a chronological analysis of the evolution of tools for science and technology stimulation in the context of the identified classification groups is carried out and an assessment of their impact on the development of science and technology in Russia is presented.

- Based on the results of a comprehensive analysis and synthesis, proposals were made on the structure of the mechanism of state incentives for the creation of centers of excellence in RF.

Directions for further research:

- review of centers of excellence at the regional level (clusters),

- review of centers of excellence in the global economic space,

- $\quad$ study of the mechanisms for the development of centers of excellence in the global economic space.

\section{References}

1. Albert, N. (2018). Assessing technology and innovation policies: introduction to the special issue. Economics of Innovation and New Technology, 27(5-6), 401-403.

2. Alexandrov, V. N. (2013). Innovative development programmers for state-owned power companies, prerequisites for creation and mechanisms of their realization. Innovations, 7, 45-51. 
3. Alpatov, G. E., \& Anokhina, E. M. (2021). Global trends in the reproduction of human capital in the tertiary education system. St Petersburg University Journal of Economic Studies, 37(1), 34-61.

4. Avdulov, A.M., Kulkin, A.M. (1996). Structure and Dynamics of Russia's Scientific and Technical Potential. Editorial URSS, Moscow.

5. Cerulli, G., Gabriele, R., \& Potì, B. (2016). The role of firm R\&D effort and collaboration as mediating drivers of innovation policy effectiveness. Industry and Innovation, 23(5), 426-447.

6. Dezhina, I. G. (2020). Scientific "Centers of Excellence" in Russian Universities: Changing Models. ECO, 4, 87-109.

7. Dezhina, I., \& Ponomarev, A. (2013). 1000 Laboratories: New Principles to Organize Scientific Research in Russia. Voprosy Ekonomiki, 3, 70-82.

8. Ivanov, V. V. (2019). Science and technology policy in the context new development strategy for Russia. Innovations, 4, 3-7.

9. Kobylińska, U., \& Lavios, J. J. (2020). Development of research on the university entrepreneurship ecosystem: trends and areas of interest of researchers based on a systematic review of literature. Oeconomia Copernicana, 11(1), 117-133.

10. Korostyshevskaya, E.M., \& Chudakov, A. Yu. (2019) Promises for cluster progression: Russian automotive market outlook. SHS Web of Conferences, 74, 2261-2424.

11. Korostyshevskaya, E. (2018). Competence centers as an instrument to commercialize technology developments in the context of Globalization. Proceedings of the 18th international scientific conference Globalization and its socio-economic consequences. University of Zilina, Slovak Republic, 2175-2182.

12. Korostyshevskaya, E. M., Samylov, I. O., \& Rumyantseva, S. Yu. (2018.) Incentives and barriers for commercialization of technological developments in Russia (empirical study). Innovations, 10, 55-62.

13. Kutsenko, E. (2015). Pilot Innovative Territorial Clusters in Russia: A Sustainable Development Model. Foresight-Russia, 9 (1), 32-55.

14. Medovnikov, D., Oganesyan, T., \& Rozmirovich, S. (2016). Candidates for the championship: Medium-sized high growth companies and state-run programs for their support. Voprosy Ekonomiki, 9, 50-66. (In Russ.)

15. Petrov, A. N., \& Kurakova, N. G. (2019). Problems of harmonization of tasks and targets of the national project 'Science'. Innovations, 4 (246), 8-16.

16. Shulgina, I.V. (1988). Science infrastructure in the USSR. Moscow, NAUKA.

17. Simachev, Yu. V., \& Kuzyk, M. G. (2020). State support of enterprises in Russia: Beneficiaries and effects. Voprosy Ekonomiki, 3, 63-83.

18. Stoianova, O., \& Bakotin, V. (2018.) The decision making support system for universitycompany-student synchronized competencies building. Proceedings of the IV International Conference on Information Technologies in Engineering Education (Inforino 2018).

19. Stoianova, O. V., Lezina, T.A., \& Ivanova, V.V. (2020). The framework for assessing company's digital transformation readiness. St. Petersburg University Journal of Economic Studies, 36(2), 243-265.

20. Stoianova, O., \& Moskaleva, V. (2021). A method and a model framework for planning R\&D changes in manufacturing enterprises. Prikladnaya informatika=Journal of Applied Informatics, 16(1), 59- 68. 
21. Tresoruk, A. A., \& Frolov, I. E. (2020). Long-term development of Russian shipbuilding with regard to the processes of defence industries diversification: model and forecast. Problems of Forecasting, 6, 119-128.

22. Zaichenko, S. (2008). Centres of Excellence in the System of Contemporary Science Policy. Foresight-Russia, 2(1), 42-50.

23. Zelentsova, N. I., Petrov, A. N., Garina, S. M., \& Tuzova, S. Y. (2017). On Expert Review of Applications for Budget Financing within the Framework of the Federal Target Program 'Research and Development in Priority Areas of Development of the Scientific-Technological Complex of Russia in 2014-2020'. Innovations, 2 (220), 86-92.

24. Zheleznyakov, A. B. (2017). Space activities of the world's countries in 2016. Innovations, 1(219), 7-14. 